\title{
EXPERIMENTAL EFFECTS OF PRE-DRIVE AROUSAL ON TEENAGE SIMULATED DRIVING PERFORMANCE IN THE PRESENCE OF A TEENAGE PASSENGER
}

\author{
Bruce Simons-Morton, ${ }^{1}$ C. Raymond Bingham, ${ }^{2}$ Kaigang Li, ${ }^{1}$ Jean Shope, ${ }^{2}$ Anuj K. Pradhan, ${ }^{1}$ \\ Emily Falk, ${ }^{3}$ Paul S. Albert ${ }^{1}$ \\ ${ }^{1}$ Eunice Kennedy Shriver National Institute of Child Health \& Human Development, Bethesda, \\ MD \\ ${ }^{2}$ University of Michigan Transportation Research Institute, Ann Arbor, MI \\ ${ }^{3}$ University of Pennsylvania, Philadelphia, PA \\ (mortonb@mail.nih.gov)
}

\begin{abstract}
Summary: Teenage passengers increase teenage driving risk, but this may be conditional on events and emotions immediately preceding driving. An experimental simulation study evaluated the effect of pre-drive arousal on risky driving in the presence of a confederate teenage passenger. In a two-by-two between-subjects design, participants were randomized to high or low pre-drive arousal and passenger present or not present conditions. Prior to the drive participants played the Nintendo Wii video game, Rock Band ${ }^{\mathrm{TM}}$. In the higharousal condition participants stood while playing high-energy Beatles songs; in the low arousal condition participants sat while playing low-energy Beatles songs. The manipulation produced differences in arousal by group. Group differences in risky driving were in the expected direction, but were not statistically significant at $p=.05$ on any of the three outcome measures, which included Failed to Stop (failing to stop at signalized intersections in the dilemma zone), Percent Time in Red (in intersections), and Pass Slow Vehicle (electing to pass a slow vehicle).
\end{abstract}

\section{BACKGROUND}

Teenagers have higher rates of motor vehicle crashes than experienced drivers (NHTSA, 2009). Fatal crash risk is particularly high under certain driving conditions, including while driving with teenage passengers (Ouimet et al., 2010). However, peer passenger effects have not consistently been shown in non-fatal crash analyses (Simons-Morton et al., 2011), suggesting that crash risk may vary according to driving conditions. Moreover, the mechanisms by which teenage passengers affect driver performance and the conditions under which this occurs are not well understood. To better understand the nature of passenger effects on the performance of teenage drivers, experimental research is needed. Previous experimental driving simulation research by our team has demonstrated that peer passenger presence reduces visual scan (Pradhan et al., 2013) and increases risky driving in the form of running red lights (Simons-Morton et al., 2013). However, additional research on the conditions under which teenage passengers affect teen driving behavior and outcomes is warranted.

Driving performance can be influenced by arousal. Even a relatively cautious driver may take unusual driving risks when excited, upset, or otherwise aroused (Taubman - Ben-Ari, 2011; van der Zwaag et al., 2012; Abdu, Shinar, Meira, 2012), including by music tempo (Brodsky, 2002). The best evidence of arousal is an increase in heart rate and one of the best ways to increase heart rate is through physical activity. Given the importance of music in the life of adolescents 
(Arnett, 1999) and its potential for establishing and maintaining particular emotional states (Saarikalli \& Erkkila, 2007) we sought to determine if differences in pre-drive arousal, manipulated in part through shared engagement in music, including physically playing an instrument, would affect driving behavior, particularly in the presence of teenage passengers.

The purpose of this research is to examine the effect on risky driving of two levels of pre-drive, positive emotional arousal coupled with peer influence. The hypotheses were: Simulated risky driving will be (1) greater in the presence vs absence of a teen passenger; (2) greater in the context of high vs low arousal; and (3) greater in the presence vs absence of a peer passenger with high vs low arousal.

\section{METHOD}

\section{DESIGN}

Young male drivers 16-18 years old with a Level 2 Michigan driver license (allowing independent driving with restrictions) were recruited $(\mathrm{n}=104)$ and provided assent and parent consent according to University of Michigan IRB approval of the protocol. Participants received compensation.

In a two-by-two between-subject design, participants $(n=81)$ were randomly assigned to one of four groups: passenger high arousal; solo high arousal; passenger low-arousal; and solo low arousal conditions. The arousal induction procedure included two conditions involving playing Beatles songs using a guitar-shaped controller and the Wii Rock Band ${ }^{\mathbf{T M}}$ video game either alone in the solo condition or with a peer confederate passenger in the passenger condition. Both conditions were emotionally positive, but varied in level of arousal. In the low-arousal conditions (solo and passenger), participants sat for 5-10 minutes while using the guitar controller to play versions of songs within the Rock Band ${ }^{\mathbf{T M}}$ Library that were pre-rated as being low-intensity: "Yellow Submarine", "Here Comes the Sun", and "Something". In the higharousal conditions (solo and passenger), participants stood while playing the up-tempo Beatles songs within the Rock Band ${ }^{\mathbf{T M}}$ Library that were pre-rated as being high-intensity, "I Want to Hold your Hand", "Can't Buy Me Love", and "Twist and Shout". At the start of the drive, the participant and confederate were instructed to concentrate on the drive and not talk (because talking could be distracting, would vary from one drive to another, and confound results).

\section{EQUIPMENT AND MEASURES}

A fixed-base high-fidelity simulator located in a dedicated lab space was used for this study. The simulator comprised a full vehicle cab (Nissan Versa) surrounded by three forward screens and one rear screen. The forward screens were projected at a resolution of $1400 \times 1050$ pixels each and the rear screen at $1024 \times 768$ pixels, providing a 120-degree forward field of view and a 40degree rear field of view. The simulator runs RTI's (Realtime Technologies, Inc., Royal Oak, MI, US) SimCreator software. The simulator system included steering feedback, road vibration, a virtual LED instrument cluster, side-view mirrors, and simulated audio. A four-camera remotemounted eye-tracking system manufactured by Smart Eye AB, Sweden was integrated into the driving simulator system and used to measure participants' eye movements and gaze location. 
The driving simulator recorded vehicle and driving performance data, up to six synchronized channels of video, and two channels of audio at $30 \mathrm{~Hz}$. Eye tracker data were recorded at $60 \mathrm{~Hz}$.

Participants completed three drives with identical scenarios: (1) 5-minute coaching/ practice drive; (2) 10-minute baseline drive; and (3) 15-minute experimental drive. All three drives included typical roadway features (e.g., four-way intersections, straight and curved rural road, expressway), but differed in the ordering of four segments, residential, rural, urban, and freeway, as well as surface features (e.g., trees, buildings). Construction barrels at intersections and junctions guided participants to the destination. The experimental drives required the participant to drive through a wide range of roadway geometries, speed limits, traffic conditions, and visual elements, including a car-passing task and multiple four-way signalized intersections.

Participants encountered signalized intersections at periodic intervals of 13-15 seconds (at 35 $\mathrm{mph}$ ), exposing them to green lights, yellow lights of different durations $(2.6 \mathrm{~s}, 3.0 \mathrm{~s}, 3.4 \mathrm{~s}$,), and red lights. The different durations of yellow lights force a choice to stop without entering the intersection, go through the intersection before the light turns red, or be caught in a 'dilemma zone'. The driving conditions and scenarios chosen were optimized to detect effects of passenger presence on simulated driving behavior. The measures of greatest interest are (1) not stopping for the red light (Failed to Stop) in six intersections; (2) percentage of time in six intersections with light red (Percent Time in Red); and (3) election to pass a slowing lead vehicle (Passed Slow Vehicle). We selected management of signalized intersections because this is a very common driving circumstance; intersection crashes are common; there is variability within and between subjects in the ways people manage intersections; and it is possible to introduce in a single drive multiple intersections, including many that place drivers in the "dilemma zone", where the light turns amber and the driver must make a quick decision to stop or go.

Heart rate was monitored with Polar heart rate monitor at baseline and arousal induction to evaluate the physiological response to the arousal induction manipulation. We also administered the Self-Assessment Manikin (SAM) instrument (Bradley \& Lang, 1994), a validated self-report measure of emotional valence and arousal. To assess individual variability in susceptibility and resistance to peer influence, we administered the measure, Resistance to Peer Influence (Steinberg \& Monahan, 2007). The following items were adapted or created for this study as manipulation checks administered in a post-drive survey. Identification with passenger was measured by six items that asked participants to indicate (1 no, 2 maybe, 3 yes) their identification with the passenger (i.e., is the passenger someone you would like to know better or someone you liked?). Passenger approval was measured by five items asking participants how likely it was ( 1 very unlikely to 5 very likely) that the passenger would approve of their involvement in five driving behaviors. Example behaviors included driving $10 \mathrm{mph}$ above the speed limit and following a slow vehicle very closely. Relative social status of passenger was assessed by one ladder item with ten responses (1 indicates the subject considered the confederate someone with the lowest social status [e.g., had the lowest respect from peers and the worst grades] and 10 indicates the subject considered the confederate someone with the highest social status [e.g., had the most respect from peers and the highest grades]).

\section{Statistical Analysis}


Of the original 104 participants, 81 were included in the current analysis after excluding 13 who participated only in the pilot activity, and 10 with incomplete data due to simulator sickness before completing the second drive. The primary driving performance comparisons were the statistical interaction effects of the experimental arousal condition (high vs. low) and passenger presence (passenger vs. solo). PROC GLIMMIX in SAS (version 9.4) was used to fit Generalized Linear Mixed Models (GLMM) where the outcomes were Failure to Stop at a Red light (binary outcome), Passing a Slow Vehicle (binary outcome), and Percent Time in Red (normal outcome). In all models, the baseline drive was used to control for individual difference in driving behavior between baseline and experiment. The GLIMMIX model follows:

$$
\begin{aligned}
& \mu=\beta_{0}+\beta_{1}(\text { BaseExp })+\beta_{2}(\text { BaseExp })(\text { PassSolo })+\beta_{3}(\text { BaseExp })(\text { Condition }) \\
& +\beta_{4}(\text { BaseExp })(\text { PassSolo })(\text { Condition })+b_{i}
\end{aligned}
$$

Where $\mu=\log \left(\frac{\pi}{1-\pi}\right)$ for Failed to Stop at a Red (binary variables) and characterizes the mean for Percent Time in Red (continuous variables). Further, BaseExp $(0=$ baseline and $1=$ experimental driving), PassSolo $(0=$ solo drive and $1=$ passenger drive $)$, and Condition $(0=$ low and $1=$ high arousal) are dichotomous variables; $b_{i}$ denotes a subject-specific random effect. For Failed to Stop at a Red light, $\exp \left(\beta_{1}\right)$ is the odds ratio from the baseline to the solo-low arousal condition, while $\beta_{2}, \beta_{3}$, and $\beta_{4}$ characterize the effect of passenger and the high arousal condition (additive and interactive effects, respectively) relative to the solo-low arousal condition. For Percent Time in Red, the $\beta$ coefficients can be interpreted as effects on the difference scale.

Repeated measures ANOVA (SAS PROC MIXED) examined heart rate differences by the interaction of induction (high vs. low arousal) $\times$ time (baseline vs. experiment) and main effects.

\section{RESULTS}

The experimental manipulation was tested by comparing mean differences between pre- and post-drive SAM scores. Scores were significantly $(\mathrm{p}<.05)$ higher for the high-arousal group compared to the low-arousal group on the "excitement" dimension $(\mathrm{M}=0.98$ for high and $\mathrm{M}=$ 0.14 for low), but not significantly different on the "happiness" dimension $(\mathrm{M}=0.70$ for high and $\mathrm{M}=0.51$ for low), as expected and consistent with the study design.

Positive mood/emotional arousal induction was evaluated with subjects' heart rates using repeated measures ANOVA. There was significant interaction $(\mathrm{F}=11.73$, $\mathrm{df}=68, \mathrm{p}<.001)$ of induction (high vs. low arousal) $\times$ time (baseline vs. experiment). In the low-arousal group, the participants' heart rates increased slightly $(\mathrm{F}=0.30, \mathrm{df}=68, \mathrm{p}>.05)$ from baseline $(\mathrm{M}=77.23$ and $\mathrm{SD}=13.46$ ) to arousal induction (Mean $=77.65$ and $\mathrm{SD}=16.50)$. However, in the higharousal group, the participants' heart rates increased dramatically $(\mathrm{F}=33.14, \mathrm{df}=68, \mathrm{p}<.001)$ from baseline $(\mathrm{M}=79.90$ and $\mathrm{SD}=11.74)$ to arousal induction $(\mathrm{Mean}=87.60$ and $\mathrm{SD}=12.73)$. At the induction stage, the heart rates of participants who experienced high-arousal induction (Mean $=87.60$ and $\mathrm{SD}=12.73)$ were significantly $(\mathrm{F}=11.18, \mathrm{df}=68, \mathrm{p}<.01)$ higher than those who had low-arousal induction (Mean $=77.65$ and $\mathrm{SD}=16.50)$. There was no significant difference $(\mathrm{F}=0.96, \mathrm{df}=68, \mathrm{p}>.05)$ in heart rate between low $(\mathrm{M}=77.23$ and $\mathrm{SD}=13.46)$ and high $(\mathrm{M}=79.90$ and $\mathrm{SD}=11.74)$ arousal groups at baseline. The heart rate results indicate 
significant physiological responses of participants to arousal induction, which indicates the success of manipulation of positive mood in this study. No significant treatment group differences were found for identification with passenger, passenger approval, and relative social status of passenger, which diminishes the possibility that group differences could be attributed to participants' perceptions of the confederate passenger.

H1: Passenger Effects. The main effects analyses (Table 1) of passenger effects for Percent Time in Red (Beta $[\beta]=3.01$, n.s.), Failed to Stop (OR=1.18, n.s.), and Passed Slow Vehicle $(\mathrm{OR}=1.22$, n.s. $)$, were generally higher in the passenger than the solo condition, but these differences were not significant.

H2. Effect of pre-drive arousal. The main effects analyses (Table 1) of the effect of pre-drive arousal for Percent Time in Red $(\beta=1.09$, n.s.) and Failed to Stop (OR $=1.34$, n.s.) were generally higher in the high-arousal compared to the low-arousal group, in line with the hypothesis, but not significant. The likelihood of Passing Slow Vehicle was somewhat lower $(\mathrm{OR}=0.70$, n.s. $)$ in the high-arousal vs the low-arousal group, counter to the hypothesis.

H3: Moderation by passenger presence of pre-drive arousal. Shown in Table 1 are the results of the primary analyses conducted to test Hypothesis 3 of moderation (interaction) of passenger presence effects on driving performance by pre-drive arousal interactions (note that the main effects shown in Table 1 are not interpretable with the interaction the model. The interactions between passenger presence and arousal for Failed to Stop (OR $=0.37$, n.s.), Percent Time in Red ( $\beta=-10.4$, n.s.), and Passed Slow Vehicle (OR 1.43, n.s.) were not significant. It could not be concluded that pre-drive arousal differentially increased risky driving in the presence of a passenger.

We evaluated the possible moderation by pre-drive scores on the measure Resistance to Peer Pressure, but none of the interactions were significant.

\section{DISCUSSION}

The effects of arousal and passenger presence on simulated risky driving behavior were in the expected directions, but not significant. The lack of significant effects could be attributed to several possibilities, of which we offer four. (1) The manipulation of arousal may not have been sufficient. Although we demonstrated a significant group difference on the SAM and heart rate measures of arousal, it is possible the magnitude of increased arousal in the high-arousal group was not sufficient or was not sufficiently sustained to increase susceptibility to peer presence or to increase risky driving. It has been shown that listening to music while driving can affect subjective ratings of arousal and respiration (van der Zwaag et al., 2012). However, we did not attempt to maintain arousal with music during the drives because we wanted to isolate the possible effect of pre-drive arousal (not confounded by an alternative explanation of the driver being potentially distracted by music during the drive). (2) In both high- and low-arousal conditions the emotional tone was positive. We chose positive tone for both arousal conditions because negative mood has been linked to aggressive driving, which could have confounded the interpretation of the results. However, comparing two positive emotion conditions may have minimized potential differences. (3) The null hypothesis that pre-drive arousal does not increase 
risky driving or social influence on risky driving may be correct, at least as measured using simulated dilemma zone scenarios. Additional research is needed. (4) Despite differences in the expected direction, the sample may have been too small to detect moderation effects (i.e., interaction) given the higher-than-expected variability in the outcome measures. Our study included group sizes of 14-24, relatively small compared to similar trials. For example, a recent study, with a sample of 204 and only two groups found an effect of happy pre-drive mood on simulated driving speed in the presence of teenage passengers (Rhodes, Pivik, \& Sutton, 2015). Taken together, our data are consistent with the hypothesis that positive arousal and peer passenger presence may influence teenage risky driving behavior, but do not provide statistically significant evidence for such effect.

Table 1. Main effects and arousal treatment condition-by-passenger presence interactions for measures of risky driving: Failed to Stop, Percent Time in Red, and Pass Slow Car $(n=81)$

\begin{tabular}{|c|c|c|c|c|c|c|}
\hline & & Variable & $\mathrm{OR} / \mathrm{B}$ & \multicolumn{2}{|c|}{$95 \% \mathrm{CI}$} & $\mathrm{p}$ \\
\hline \multirow{7}{*}{$\begin{array}{c}\text { Failed to Stop } \\
\text { (Odds Ratio } \\
{[\text { OR]) }}\end{array}$} & \multirow{6}{*}{ Main effects ${ }^{\mathrm{b}}$} & Experiment $^{\mathrm{a}}$ & 0.18 & 0.09 & 0.35 & $<.001$ \\
\hline & & Baseline $^{\mathrm{a}}$ & ref & & & \\
\hline & & Passenger & 1.18 & 0.59 & 2.34 & 0.65 \\
\hline & & Solo & ref & & & \\
\hline & & High Arousal & 1.34 & 0.68 & 2.63 & 0.40 \\
\hline & & Low Arousal & ref & & & \\
\hline & Interaction $^{\mathrm{b}}$ & $\begin{array}{l}\text { Passenger } \times \\
\text { Arousal }\end{array}$ & 0.37 & 0.09 & 1.48 & 0.16 \\
\hline \multirow{7}{*}{$\begin{array}{l}\text { Percent time in } \\
\text { Red (Beta, }[\beta])\end{array}$} & \multirow{6}{*}{ Main effects ${ }^{b}$} & Experiment & -17.48 & -23.90 & -11.06 & $<.001$ \\
\hline & & Baseline & ref & & & \\
\hline & & Passenger & 3.01 & -3.92 & 9.94 & 0.39 \\
\hline & & Solo & ref & & & \\
\hline & & High Arousal & 1.09 & -5.70 & 7.88 & 0.75 \\
\hline & & Low Arousal & ref & & & \\
\hline & Interaction $^{\mathrm{b}}$ & $\begin{array}{l}\text { Passenger } \times \\
\text { Arousal }\end{array}$ & -10.42 & -24.30 & 3.45 & 0.14 \\
\hline \multirow{7}{*}{$\begin{array}{l}\text { Pass slow vehicle } \\
\text { (OR) }\end{array}$} & \multirow{6}{*}{ Main effects ${ }^{b}$} & Experiment & 0.49 & 0.13 & 1.81 & 0.28 \\
\hline & & Baseline & ref & & & \\
\hline & & Passenger & 1.22 & 0.31 & 4.78 & 0.77 \\
\hline & & Solo & ref & & & \\
\hline & & High Arousal & 0.70 & 0.18 & 2.68 & 0.60 \\
\hline & & Low Arousal & ref & & & \\
\hline & Interaction $^{\mathrm{b}}$ & $\begin{array}{l}\text { Passenger } \times \\
\text { Arousal }\end{array}$ & 1.43 & 0.09 & 22.75 & 0.80 \\
\hline
\end{tabular}

${ }^{a b}$ The main effect and interaction analyses considered the experimental drive, controlling for baseline and Experiment, which measured the change in the mean from baseline to solo/low-arousal condition, which can be interpreted as changes due to either learning effects or being exposed to the low-arousal intervention condition.

\section{ACKNOWLEDGEMENT}

This research was supported in part by the Intramural Research Program of the Eunice Kennedy Shriver National Institutes of Child Health and Human Development (NICHD), contract \# HHSN27520100007C. 


\section{REFERENCES}

Abdu, R., Shinar D., Meira, N. (2012). Situational state and driving. Transportation Research Part F, 15, 575-580.

Arnett, J. J. (1999). Adolescent storm and stress, reconsidered. American Psychologist, 54(5), 317-326.

Bradley, M.M. \& Lang, P.J. (1994). Measuring emotion: the self-assessment Manikin and the semantic differential. Journal of Behavioral Therapy \& Experimental Psychiatry, 25(1), 49-59.

Brodsky, W. (2002). The effects of music temp on simulated driving performance and vehicle control. Transportation Research Part F, 4, 219-241.

National Highway Traffic Safety Administration (NHTSA). (2009). Traffic Safety Facts. (November 2009) DOT HS 811 218. Washington, DC: National Highway Traffic Safety Administration. http://www-nrd.nhtsa.dot.gov/Pubs/811218.PDF

Ouimet, M.C., Simons-Morton, B.G., Zador, P.L., Lerner, N.D., Freedman, M., Duncan, G.D., \& Wang, J. (2010). Using the U.S. National Household Travel Survey to estimate the impact of passenger characteristics on young drivers' relative risk of fatal crash involvement. Accident Analysis and Prevention, 42(4), 689-694.

Pradhan, A.K., Li, K., Bingham, Simons-Morton B.G., Ouimet, M.C., Shope, J.T. (2014). Peer passenger influences on male adolescent drivers' visual scanning behavior during simulated driving. Journal of Adolescent Health, 54, S42-S49.

Rhodes, N., Pivik, K., Sutton M. (2014). Risky driving among young male drivers: the effects of mood and passengers. Transportation Research Part F, 28, 65-76.

Saarikallio, S., \& Erkkila, J. (2007). The role of music in adolescents' mood regulation. Psychology of Music, 35(1), 88-109.

Simons-Morton, B.G., Ouimet, M.C., Zhang, Z., Lee, S.L., Klauer, S.E., Wang, J., Chen, R., Albert, P.E., \& Dingus, T.E. (2011). The Effect of passengers and risk-taking friends on risky driving and crashes/near crashes among novice teenagers. Journal of Adolescent Health, 49(6), 587-593.

Simons-Morton, B. G., Bingham, C. R., Ouimet, M. C., Pradhan, A., Falk, E., Li, K. -G., Green, P., Almani, F., \& Shope, J. (2014). Experimental effects of injunctive norms on simulated risky driving among teenage males. Health Psychology, 33(7), 616-627.

Steinberg, L., \& Monahan, K. C. (2007). Age differences in resistance to peer influence. Developmental Psychology, 43(6), 1531-1543.

Taubman - Ben-Ari Taubman-Ben-Ari, O. (2012). The effects of positive emotion priming on self-reported reckless driving. Accident Analysis and Prevention, 45, 718-725.

Van der Zwaag, M.D., Dijksterhuis, C., de Waard, D, Mulder B.L.J.M., Weterink, J.H.D.M., $\&$ Brookhuis, K.A. (2012). The influence of music on mood and performance while driving. Ergonomics, 55(1), 12-22. 